\title{
\&10 АКТУАЛЬНАЯ
}

Грудцына Л.Ю., Лагуткин А.В.

\section{РЕФОРМИРОВАНИЕ ВЫСШЕГО ОБРАЗОВАНИЯ: КЛАСТЕРНЫЙ ПОДХОД}

\begin{abstract}
Аннотация: Перед отечественными вузами остро стоит проблема внедрения инноваций в условиях зарождающегося инновационного типа экономики, которые способны сделать вузы более конкурентоспособным и сформировать положительную национальную конкурентоспособность. Современная система образования находится в последние годы в постоянном реформировании и обновлении. По крайней мере, об этом много говорят и пишут. На повестке дня разрушение не только технического образования, но и гуманитарного. Кризис очевиден. Поступательная, временами скачкообразная реформа высшего образования в стране, в конечном счете, должна привести к позитивным результатам. Однако непродуманность, отсутствие экспертной базы в случае слияния зачастую разнородных ВУзов для создания федеральных, национальных или исследовательских университетов, т.е. градация, на мой взгляд, покоящаяся на весьма зыбких основаниях, вряд ли приведет к конструктивным результатам. В ходе проведения научного исследования проблемы создания кластерной системы высшего образования в современной России авторами статьи использовались современные общенаучные и специальные методы познания, в частности: анализ, синтез, системный, сочиологический, историко-юридический, аксиоматический, метод сравнительного правоведения, анализа документов и т.д. Их применение в сочетании с последними достижениями юридической, философской, политологической и социологической мысли позволило выявить и проанализировать социально-правовую природу института образования как части культуры, а также выявить основные направления модернизации системы высшего образования в Российской Федерации. Суть предлагаемой реформы заключается в следующем - создание кластерной системы высшего технического образования в стране.В целом следует одобрить укрупнение отраслевых вузов, однако данный процесс нуждается в корректировке - необходимо не просто укрупнять, но продуманно создавать кластерные системы, в которых укрупненные отраслевые вузы не будут сами по себе, но станут в условиях инновационной экономики России неотъемлемой частью единого технологического проекта, цель которого - логично объединить все этапы научного знания и производства, например:а) наращивание базы знаний и обеспечение мирового уровня научных исследований и разработок в сфере прорывных технологий путем развития университета как исследовательского центра, осуществляющего эффективную интеграцию образования и научных исследований; б) написание конкретных образовательных программ, по которым будет проходить обучение будущих специалистов, кроме того, диалог с основными работодателями, включая анкетирование, проведение семинаров, конференций и заседаний экспертных групп;в) воспроизводство высокопрофессиональных кадров (под конкретные виды деятельности производства, на конкретные рабочие места), которые займутся созданием и распространением конкурентоспособных технологий.Представляется, что аналогичную систему кластерных вУзов вполне возможно применить для подготовки специалистов в агропромышленном комплексе. Например:Сельскохозяйственный ВУз - специализация растениеводство - вУз по подготовке специалистов пищевой промышленности; $C$ ельскохозяйственный вУз - специализация растениеводство - текстильный вУз - ВУз по подготовке специалистов в области швейной промышленности;Сельскохозяйственный вУз - специализация в области животноводства - ВУз по подготовке специалистов мясо-молочной промышленности;Сельскох озяйственный вУз - специализация в области животноводства - вУз по подготовке специалистов кожевенной, обувной и кожгалантерейной промышленности.Все перечисленные ВУзы создаются с той же целью, что и в геолого-горно-металлургической академии. Вместе с тем, удастся сохранить бесценные
\end{abstract}


Административное и муниципальное право 7 (79) 2014

составляющие ВУзов: их учебный и научный потенциал, т.е. школы, который сложились на протяжении многих лет, в том числе, поэтому эффективно работающие.

Ключевые слова: образовательный кластер, высшее образование, кластерная система, исследовательский университет, высшее техническое образование, реформа образования, национальный университет, горный университет, сельскохозяйственный вуз, инновации в образовании

A вторы статьи, не претендуя на истину в последней инстанции, предлагают свое видение проблем современного образования и, главное, комплексные варианты выхода из сложившейся ситуации. Главное - не замыкаться только на проблемах образования как части культуры, которое, как и любой другой институт социума, гражданского общества, является лишь частью сложной системы функционирования государства и общества.

Кластерное обучение является сравнительно новым направлением в профессиональной педагогике, его внедрение в процесс подготовки требует определения педагогических условий и экспериментальной проверки эффективности формирования компетентного специалиста. ${ }^{1}$ Иными словами, сначала нужно подготовить профессионального педагога, который будет обучать студентов - будущих специалистов. Роль вуза в кластере сводится к тому, чтобы производить инновационный товар. Что это значит на практике? Научно-исследовательские институты и производственные учреждения региона становятся базой практик и получают возможность участвовать в формировании специалиста на собственной научно-учебной базе, в соответствии со своими потребностями и перспективами развития. ${ }^{2}$

Российская сфера образования не может порождать новые виды деятельности и быть инновационным, поскольку привязан к старым организационным структурам и государственным институтам (которые были сформированы еще в 1960-е гг. и согласно которым осуществлялась подготовка кадров в отрасли экономики). Сегодня очевидно, что российские вузы не охватывают

1 См.: Гаврилова О.Е., Шагеева Ф.Т., Никитина Л.Л. К вопросу о подготовке специалистов-конструкторов швейного производства в условиях образовательного кластера. - [электронный ресурc]. URL: http:// conference.kemsu.ru/ GetDocsFile?id=13537\&table= papers_ file\&type $=0 \& \operatorname{conn}=$ confDB (дата обращения 02.01.2010г.).

2 См.: Трушников Д.Ю., Трушникова В.И. Воспитание в условиях университетского кластера и ценностные студенчества: Статья. [электронный ресурс]. URL: http:// conference. tsogu.ru/static/articles/2009/01/_.doc (дата обращения 04.01.2010г.).

этап «подготовки кадров» и не способны конкурировать на глобальном рынке, в отличие от западных университетов, которые, помимо того, что оказывают образовательные услуги, в том числе, в сфере «бизнес-процесса», являются еще крупными научными центрами, занимающимися исследованиями как теоретического, так и прикладного характера. Несмотря на предоставленную несколько лет назад возможность вузам заниматься предпринимательской деятельностью, в силу существующих правовых и организационных лакун в институциональной системе и неотлаженного механизма оптимизации налогообложения в сфере образования, на данный момент времени довольно затруднительно говорить о четкой схеме коммерциализации вузовской науки, что также влияет на степень конкурентоспособности отечественного университета.

Суть предлагаемой реформы заключается в следующем - создание кластерной системы высшего технического образования в стране.

Известно, что кластером называют систему, объединяющую ее компоненты по тем или иным признакам (однородную по отдельным признакам). Именно так и была создана в 1918 году Московская горная академия, имевшая в своем составе: геологоразведочный, горный, металлургический и др. факультеты. Возврат к истокам высшего образования в СССР позволит охватить единой цепью систему всех трех базовых отраслей народного хозяйства России.

Не секрет, что экономика страны покоится на собственной минерально-сырьевой базе, мы обладаем широчайшим спектром видов полезных ископаемых и их несопоставимыми объемами, по сравнению с другими странами. Поэтому объединение этих отраслей в единый народнохозяйственный комплекс целесообразно и оптимально для нашей экономики. Частично это учитывалось и в советское время при создании отраслей черной и цветной металлургии, в которых успешно функционировали добывающие и металлургические предприятия, за исключением первой фазы предлагаемой цепочки - геологии.

Тенденция создания сложных интегрированных образовательных систем (образовательных 
кластеров) путем укрупнения отраслевых государственных вузов путем реорганизации (в форме присоединения) в последние два года приобрела системный характер. Например, к Национальному исследовательскому технологическому университету «МИСиС» были присоединены Российский государственный геологоразведочный университет имени С. Орджоникидзе и Московский государственный горный университет (в настоящее время заканчивается процедура реорганизации в форме присоединения). ${ }^{3}$ Тремя годами ранее, распоряжением Правительства РФ от 30 июля 2009 г. № 1073р была утверждена Программа создания и развития ФГОУ ВПО «МИСиС» на 2009-2017 гг., целью которой является формирование современного образовательного учреждения высшего профессионального образования, которое подготавливает специалистов с высшим образованием всех уровней, а также осуществляет научные исследования и разработки мирового класса и вносит, таким образом, значительный вклад в развитие системообразующих отраслей экономики, науки и образования России. ${ }^{4}$

Слияние вузов, полностью охватывающих тот или иной цикл производства, действительно, назрело давно. В условиях послеперестроечного развала российского производства (заводов, фабрик) и переживаемого в последние годы (вполне предсказуемого) демографического кризиса (в том числе, рабочей силы, профессиональных кадров) институт образования и выпуск профессиональных и востребованных кадров становится сейчас едва ли не единственным спасительным сценарием для современной России. Кадры, действительно, решают все.

Что же такое образовательный кластер? Кластер (англ. cluster - скопление) - это объединение нескольких однородных элементов, которое может рассматриваться как самостоятельная единица, обладающая определенными свойствами. ${ }^{5}$ Кластер - это группа соседствующих взаимосвязанных компаний и связанных с ними организаций, действующих в определенной сфере и характеризующихся общностью деятельности и

\footnotetext{
3 Согласно приказу Минобра России от 14 мая 2012 г. № 398.

4 См.: Грудцына Л.Ю. Государственно-правовой механизм формирования и поддержки институтов гражданского общества в России / Автореф. дисс... докт. юрид. наук / Российский университет дружбы народов (РУДН). Москва, 2009.

5 Википедия: Свободная энциклопедия. [электронный реcypc]. URL: http://ru.wikipedia.org/wiki/\%D0\%9A\%D0\%BB\%D 0\%B0\%D1\%81\%D1\%82\%D0\%B5\%D1\%.
}

взаимодополняющих друг друга. ${ }^{6}$ Понятие кластера в западной литературе было введено в экономическую теорию М. Портером: «кластер - это сконцентрированные по географическому признаку группы взаимосвязанных компаний, специализированных поставщиков, поставщиков услуг, фирм в соответствующих отраслях, а также связанных с их деятельностью организаций».7 Таким образом, для того чтобы быть кластером, группа географически соседствующих взаимосвязанных компаний и связанных с ними организаций должна действовать в определенной сфере, характеризоваться общностью деятельности и взаимодополнять друг друга.

Образовательный кластер - это совокупность взаимосвязанных учреждений профессионального образования, объединенных по отраслевому признаку и партнерскими отношениями с предприятиями отрасли; это система обучения, взаимообучения и инструментов самообучения в инновационной цепочке «наука - технологии бизнес», основанная преимущественно на горизонтальных связях внутри цепочки. ${ }^{8}$ Наполнение модели образовательного кластера должно происходить через социальное партнерство, которое в условиях образовательного кластера будет эффективным, если: ${ }^{9}$ - все уровни образования одной отрасли находятся в преемственном соподчинении на основе сквозных образовательных программ; - образовательные программы создаются с учетом требований профессиональных стандартов, разработанных представителями отрасли; - коллективы учебного заведения (учебных заведений) и предприятий взаимодействуют на основе принципа корпоративности. ${ }^{10}$ В целом различаются три широких определения кластеров, каждое из которых подчеркивает основную черту их функционирования:

\footnotetext{
6 См.: Громыко Ю.В. Что такое кластеры и как их создавать? // Альманах «Восток». - 2007. - Вып.1. - [электронный реcypc]. URL: http://www.situation.ru/app/j_artp_1178.htm.

7 См.: Портер М. Конкуренция. М.: Издат. дом «Вильяме», 2003.

8 Нанотехнологический словарь РОСНАНО. - [электронный ресурс]. URL: http://www.rusnano.com/Term.aspx/ Show/15134.

9 См.: Яворский О.Е. Образовательный кластер как форма социального партнерства техникума и предприятий газовой отрасли: диссертация ... кандидата педагогических наук: 13.00.01. - Казань, 2008. - 253 с.

10 См.: Смирнов А.В. Образовательные кластеры и инновационное обучение в вузе. Монография. - Казань: РИЦ «Школа», 2010. - С. 5-6.
} 
Административное и муниципальное право 7 (79) 2014

a) регионально ограниченные формы экономической активности внутри родственных секторов, обычно привязанные к тем или иным научным учреждениям (НИИ, университетам и т.д.);

б) вертикальные производственные цепочки, узко определенные секторы, в которых смежные этапы производственного процесса образуют ядро кластера (например, цепочка «поставщик-производитель-сбытовик-клиент»).

В эту же категорию попадают сети, формирующиеся вокруг головных фирм;

в) отрасли промышленности, определенные на высоком уровне агрегации (например, «химический кластер») или совокупности секторов на еще более высоком уровне агрегации (например, «агропромышленный кластер»). ${ }^{11}$

Опираясь на изложенное, предлагается создать супервуз на основе геологоразведочного, горного и металлургического университетов, в котором общеобразовательные кафедры можно будет объединить. Такой ВУЗ, например, Академия, будет осуществлять инженерно-кадровое обеспечение народно-хозяйственного комплекса, на котором, повторюсь, зиждется экономическое благополучие России, и, в первую очередь, ее национальная безопасность.

И в самом деле, геологи отыскивают и осуществляют нормативноправовое оформление разведанного месторождения. Горняки принимают это месторождение от геологов и осуществляют комплекс горных работ, включая выемку породы, проходку горных и вспомогательных выработок, их крепление и выдачу добытого сырья на поверхность. После нескольких стадий обогащения, в зависимости от типа сырья и содержания полезного ископаемого, продукция подвергается металлургической переработке, которая, на мой взгляд, является окончательным переделом процесса обогащения.

Учебно-научный фундамент этих трех ВУЗов позволит создать надструктурное управляющее звено, предназначенное для изучения конъюнктуры рынка, прогнозирования и планирования на соответствующие периоды времени, подготовку инженерных кадров по всем трем направлениям, а также координации научных работ в интересах указанных отраслей. Таким образом, мы можем определить потребность внешнего и внутреннего рынков в тех или иных видах продукции, что по-

11 См.: Цихан Т.В. Кластерная теория экономического развития // Теория и практика управления. 2003. № 5. зволит количественно и качественно спланировать подготовку специалистов этих отраслей.

Представляется, что аналогичную систему кластерных ВУЗов вполне возможно применить для подготовки специалистов в агропромышленном комплексе. Например:

Сельскохозяйственный ВУЗ - специализация растениеводство - ВУЗ по подготовке специалистов пищевой промышленности;

Сельскохозяйственный ВУЗ - специализация растениеводство - текстильный ВУЗ - ВУЗ по подготовке специалистов в области швейной промышленности;

Сельскохозяйственный ВУЗ - специализация в области животноводства - ВУЗ по подготовке специалистов мясо-молочной промышленности;

Сельскохозяйственный ВУЗ - специализация в области животноводства - ВУЗ по подготовке специалистов кожевенной, обувной и кожгалантерейной промышленности.

Все перечисленные ВУЗы создаются с той же целью, что и в геолого-горно-металлургической академии. Вместе с тем, удастся сохранить бесценные составляющие ВУЗов: их учебный и научный потенциал, т.е. школы, который сложились на протяжении многих лет, в том числе, поэтому эффективно работающие.

Кластер как механизм инновационного управления развитием системы общего образования позволяет обеспечить эффективность деятельности каждого образовательного учреждения, входящего в него. В том числе: развитие социального партнёрства, привлечение внебюджетных средств в сферу образования, появление ресурсов для инновационной подготовки, переподготовки и повышения квалификации педагогических кадров, качественно новые результаты образования, основанные на непрерывном развитии ребенка, позволяет улучшить внешний облик учреждений.

На наш взгляд, создание какой-либо инновации влечет за собой, по меньшей мере, три проблемы: во-первых, кадровую проблему (нет специалистов, который на должном уровне смогут заниматься дальнейшим развитием инновационного продукта), во-вторых, нет рынков сбыта инновационной продукции (не проработаны механизмы, куда и кому сбывать товар, идеи и т.д.), в-третьих, сразу после создания инновации в конкретной отрасли экономики нет еще самой технологии (она не отработана), технологической базы, необходимой для поддержания дальнейшего развития инноваций. Более того, при формировании образовательного 
кластера решается ряд вопросов, относящихся к сфере взаимодействия рынка образования и рынка труда. Во-первых, выстраивается механизм заказа, т.е. происходит четкое формулирование требований, которые появляются у общества, включая бизнес. Бизнес осознает важность вложений инвестиций в человеческий капитал, что отражается в позитивных тенденциях как на макро-, так и на микроуровнях. Запускается механизм «социального лифта», т.е. возрастает социальная мобильность студента как субъекта образовательного кластера. Происходит регулирование рынка труда отрасли в рамках которой создан образовательный кластер в соответствии с существующими потребностями. При недостатке четких механизмов взаимодействия государства, работодателя и выпускника, наблюдается отсутствие централизованного распределения рабочей силы по отраслям и сферам занятости, а выпускнику практически полностью отдано право и возможности поисков работы. Причем участие работодателя в процессе подготовки кадров на уровне высшего образования практически отсутствует, если не принимать во внимание создание и функционирование образовательного кластера, не только как формы социального партнерства, но и перспективной формы интеграции науки, бизнеса и государства.

Итак. В целом следует одобрить укрупнение отраслевых вузов, однако данный процесс нуждается в корректировке - необходимо не просто укрупнять, но продуманно создавать кластерные системы, в которых укрупненные отраслевые вузы не будут сами по себе, но станут в условиях инновационной экономики России неотъемлемой частью единого технологического проекта, цель которого - логично объединить все этапы научного знания и производства, например:

а) наращивание базы знаний и обеспечение мирового уровня научных исследований и разработок в сфере прорывных технологий путем развития университета как исследовательского центра, осуществляющего эффективную интеграцию образования и научных исследований;

б) написание конкретных образовательных программ, по которым будет проходить обучение будущих специалистов, кроме того, диалог с основными работодателями, включая анкетирование, проведение семинаров, конференций и заседаний экспертных групп;

в) воспроизводство высокопрофессиональных кадров (под конкретные виды деятельности производства, на конкретные рабочие места), которые займутся созданием и распространением конкурентоспособных технологий.

Очевидно, что в рамках формированию новых стандартов образования в сфере высоких технологий необходимо проводить широкомасштабное изучение опыта ведущих технологических университетов мира по формированию компетентностей своих выпускников, формировать образовательные программы и системы показателей качества, позволяющие обеспечить выпускникам требуемый уровень подготовки с учетом прогнозирования перспектив развития высокотехнологичных производств.

Приведем пример логически выверенной и замкнутой цепочки производства, размещаемой, например, в горном кластере. Геологи разведывают, находят и регистрируют месторождение в установленном законодательстве порядке. Затем зарегистрированное месторождение, определенное по его объемам и горно-геологическим условиям, передается горнякам, которые решают, каким способом добывать данное полезное ископаемое, строят шахту или карьер (если речь идет об угле, то разрез), ведут процесс добычи и несколько стадий обогащения. Львиную долю полезных ископаемых, добываемых в недрах, составляют металлы - черные, цветные и т.п. Поэтому продолжением данной кластерной цепочки станет переработка металлов: добытые и обогащенные в несколько фаз полезные ископаемые передаются металлургам. ${ }^{12}$ Аналогичная цепочка, как верно отмечает А.В. Лагуткин, может быть и в области сельского хозяйства: например, Растениеводство - текстильный институт и швейный. Или животноводство и последующие направления: мясомолочное - кожевенная - кожгалантерейная, обувная или швейная. ${ }^{13}$ Подобных вариантов много. Все логично и просто.

На примере гуманитарного образования, в частности, юридического и экономического, также можно привести несколько примеров: получение студентами общетеоретических знаний - специализация - производственная практика в органах государственной власти или коммерческих структурах - получение практических профессиональных отраслевых навыков - устройство на работу по специальности. Скорее, следует отталкиваться от обратного, а именно: переосмыслить существовав-

12 См.: Лагуткин А.В. Вузы экстра-класстера // Московский Комсомолец. 2012. № 26130. 28 декабря.

13 См.: Лагуткин А.В. Там же. 
ший в СССР положительный опыт распределения на рабочие места выпускников вузов (по желанию самих выпускников) и исходить из экономического анализа и математического прогноза потребностей в специалистах в отраслях экономики. В соответствии с прогнозами ведущие отраслевые вузы страны будут готовить специалистов, уменьшая, таким образом, риск переизбытка на рынке ненужных профессий. У юристов, например, координирующей структурой можно сделать Ассоциацию юристов России или Союз ректоров России - данные организации могли бы стать структурно определяющей, центральной информационной средой в образовательном кластере в сфере юриспруденции.

Попробуем провести другую аналогию спроецировать созданную Г. Фордом систему производительности труда, гениально примененную им в автопромышленности, на образовательные кластеры. Итак, в основе фордовской системы лежала определенная концепция, сформированная из следующих положений:

1) Неправильно начинать производство, пока не усовершенствован сам фабрикат (конструкция изделия). Применительно к образовательной сфере этот тезис звучит так: прежде чем набирать студентов на конкретные специальности необходимо провести анализ и прогнозирование, понять, сколько специалистов в конкретной отрасли экономики требуется сейчас, как этот показатель изменится через 5 лет, через 10 лет и т.д. Важны здесь и сами образовательные программы (как и чему учить). В данном случае уместна аналогия студента - будущего специалиста с конкретной маркой автомобиля «Форд», а в качестве фабриката (конструкции изделия) выступают образовательные программы, по которым учат студента (пройденный им образовательный цикл и на выходе - контроль качества - уровня полученной квалификации и знаний, диплом). Когда готов фабрикат (образовательный цикл), можно запускать производство (специалистов).

2) Производство должно происходить из самого продукта. Методики обучения должны «подстраиваться» под конечную цель - получаемую обучаемым профессию и возможности с ней реализоваться. Образованного человека условно можно сравнить с хорошей машиной: если есть хорошие знания и профессионализм, при их востребованности современным обществом и экономикой, человек всегда находит себе достойную работу и приносит экономическую пользу себе и государству. Если машина собрана некачественно и ломается (чело- век недостаточно образован и мотивирован, чтобы выполнять свою работу хорошо) - она не поедет. Прохождение ТО автомобилем (аналогия - повышение специалистом своей квалификации, уровня знаний и т.д.) продлевает его срок службы.

3) Фабрика, организация, сбыт и финансовые соображения сами приспосабливаются к фабрикату. В данном случае Г. Форд применил революционную идею, когда в процессе сборки автомобиль (его кузов) перемещался на конвейере, а обслуживающие его рабочие (вместо того, чтобы приносить к неподвижному объекту сборки детали, как это было принято), находясь каждый на своем месте, монтировал конкретную деталь, не теряя времени, по мере приближения к нему объекта сборки на конвейере (конвейерная сборка). В образовании начинать нужно с необходимых и востребованных экономикой результатов, с запросов работодателей и постановки государственных целей и задач восстановления отраслей экономики (запроса специалистов конкретных специальностей).

4) Остриями в фабричном предприятии являются человек и машина, вместе выполняющие работу. Если человек не подходящий, то и машина не в состоянии выполнять работу правильно, и наоборот. Если человек не обучен качественно или его обучение прошло в невостребованном для отрасли экономике ключе, то как специалист он будет непригоден либо пригоден частично к выполнению работы.

5) Экономия на издержках производства. По Г. Форду, снижение издержек производства осуществляется по нескольким направлениям. Первым из них может быть признано сбережение материалов в двух аспектах: как собственно сбережение материала и как сбережение труда (по К. Марксу), который в нем овеществлен. Второе направление снижения издержек производства - механизация трудовых процессов. Повторимся, высшим достижением на заводах Г. Форда было внедрение конвейерной сборки, принципиально изменившее характер выполнения сборочных операций. Третье направление снижения себестоимости - это упрощение перевозок. Четвертым направлением удешевления производства являлась стандартизация как сочетание наилучших способов производства, позволяющих производить товар в достаточном количестве и по наименьшей цене для потребителя, что дает производителю огромные прибыли.

Если обратиться к истории, то можно отметить, что система подготовки рабочей силы в социалистической экономике базировалась на концепции 
государственной собственности на рабочую силу. В границах этой концепции предполагалось, что государство, во-первых, финансирует подготовку рабочей силы в нужном объеме и нужного качества; во-вторых, централизованно распределяет ее по отраслям и сферам занятости. ${ }^{14}$ Конечной целью государства явилось присвоение прибавочной стоимости. Созданную в результате систему профессионального образования, которая осуществляла подготовку кадров в рамках начального (ПТУ), среднего (техникумы) и высшего образования (отраслевые институты), отличали, с одной стороны, направленность на профессионально-техническое обучение и подготовку квалифицированной рабочей силы для отраслей материального производства, а с другой, - преимущественная ориентация на узкие профессионально-специализированные области, что приводило к формированию узкоспециализированной рабочей силы, привязанности работника к своему рабочему месту и к специальности. ${ }^{15}$ Такая система формального образования обеспечивала достаточно высокий общий уровень образования и подготовки работника. Именно это достоинство советского образования способствовало успешному ходу процесса всеобщего переобучения работников в начале 1990-х гг. - в период, когда системная трансформация экономики России сопровождалась обесценением человеческого капитала, накопленного в предыдущую эпоху. Несоответствие структуры имеющегося образовательного потенциала как по объему, так и по качеству, структуре спроса, предъявляемого рынком труда, заставило работников предпринимать активные усилия, направленные на оптимизацию запасов человеческого капитала.

В современной России начинать создание образовательного кластера, на наш взгляд, нужно с унификации образовательных программ, по которым будут обучаться студенты - будущие специалисты отрасли, делая уклон в сторону приближения теории и практики обучения к конкретным производственным условиям. Механизация трудовых процессов применительно к образованию может выражаться в создании программ и курсов электронного (дистанционного) обучения.

14 См.: Квадрициус Н.В. Двухуровневая система высшего образования: Оценка с позиций теории человеческого капитала// Вестник СПбГУ. Сер. 5. 2006. Вып. 4. С. 151-156.

15 См.: Капелюшников Р.И. Ценится ли на российском рынке человеческий капитал? (http://www.demoscope.ru/ weekly/2005/0193/tema01.php).
6) Повышение качества, формирование цен и прибыли. В компании Г. Форда велась постоянная борьба за простоту, надежность и дешевизну производимых автомобилей. Каждая отдельная часть автомашины должна быть сменной, чтобы в будущем, если понадобится, ее можно было заменить усовершенствованной частью, машина же в целом должна служить неограниченное время.

Аналогия в образовании - назревшая потребность общества в формировании нового университета, а именно университета инновационного типа, деятельность которого вполне отвечала бы сегодняшним реалиям. Достоинство вузовского образования нового времени - это не только его качество, не только его способность интегрироваться в национальную инновационную систему путем развития вузовской науки, но и ориентация на рынок труда. Образовательный рынок и рынок труда в значительной степени рассогласованы: наблюдается отставание предложений образовательных услуг от потребностей рынка труда, плохо сопряжены сферы труда и образования с точки зрения соответствия классификации профессий и специальностей. Все это отражается и на состоянии образовательной системы, находящейся на пути модернизации, и на состоянии рынка труда, который при наличии огромного числа лиц, получивших высшее образование, не может удовлетворить свои потребности в нужных специалистах. По причине полной структурной перестройки экономики в нашей стране рынок труда полностью трансформировался. Он столкнулся с таким явлением, как «инфляция квалификаций», когда специальность работника, зафиксированная в дипломе, не соответствует занимаемой должности. Вопреки ожиданию, что включится механизм саморегуляций, эта ситуация на рынке труда не привела к существенным преобразованиям на рынке образовательных услуг. Напротив, с каждым годом обнаруживается все больший разрыв между количеством выпускаемых специалистов и реально требуемых работодателем специальностей. Кризис в этой сфере очевиден.

Построение образовательного кластера связано с необходимостью объединить в рамках одной (территориальной, функциональной) зоны бизнес-проекты в конкретной образовательной области, фундаментальные разработки и современные системы проектирования новых технологий, методик, интеллектуальных продуктов и подготовку 
производства этих продуктов. ${ }^{16}$ Для работодателязаказчика образовательных услуг образовательный кластер является фабрикой комплексного практико-ориентированного знания, позволяющего определить зоны приоритетных инвестиционных вложений. ${ }^{17}$ Интеграция в образовательном кластере понимается не только как формальное объединение различных структур известной триады «образование - наука - производство», а как нахождение новой формы сопряжения их потенциалов с целью достижения сверх эффекта в решении поставленных задач. ${ }^{18}$

В целях активизации развития кластеров в полной мере должен быть использован потенциал особых экономических зон, связанный с финанси- рованием развития инфраструктуры, осуществляемым из бюджетных источников, а также льготным налоговым режимом ${ }^{19}$ и обеспечиваемым привлечением «якорных» резидентов - крупных компаний, конкурентоспособных на отечественном и мировом рынках, выступающих в качестве ядра развивающихся кластеров. ${ }^{20}$ Также, дополнительная поддержка финансирования инфраструктуры инновационных кластеров из средств федерального бюджета может быть обеспечена в результате предоставления муниципальному образованию территории его базирования статуса наукограда Российской Федерации в соответствии с Федеральным законом «О статусе наукограда Российской Федерации» от 7 апреля 1999 г. № 70-ФЗ. ${ }^{21}$

\section{Библиография:}

1. Асадуллин Р.М. Интеграция как новая форма сопряжения образования, науки и практики в регионе // Аккредитация в образовании. - 2009. - № 32. - С. 16-18.

2. Вознесенская Е.Д. Чередниченко Г.А. Высшее образование в профессиональных траекториях молодых рабочих // Вопросы образования. 2012. № 4. С. 40-41.

3. Гаврилова О.Е., Шагеева Ф.Т., Никитина Л.Л. К вопросу о подготовке специалистов-конструкторов швейного производства в условиях образовательного кластера. - [электронный ресурс]. URL: http://conference. kemsu.ru/ GetDocsFile?id=13537\&table= papers_file\&type=0\&conn=confDB (дата обращения 02.01.2010 г.).

4. Громыко Ю.В. Что такое кластеры и как их создавать? // Альманах «Восток». - 2007. — Вып. 1. [электронный ресурc]. URL: http://www.situation.ru/app/j_artp_1178.htm.

5. Грудцына Л.Ю. Государственно-правовой механизм формирования и поддержки институтов гражданского общества в России / Автореф. дисс... докт. юрид. наук / Российский университет дружбы народов (РУДН). Москва, 2009.

6. Грудцына Л.Ю. Реформирование системы аттестации научных и научно-педагогических кадров: некоторые предложения // Государство и право. 2013. № 3. С. 5-19.

7. Зернов В. Высшее образование как ресурс инновационного развития России // Высшее образование в России. - 2008. - № 1. - С.12-22.

8. Капелюшников Р.И. Ценится ли на российском рынке человеческий капитал? (http://www.demoscope. ru/weekly/2005/0193/tema01.php).

9. Карамурзов Б.С. Непрерывное профессиональное образование в университетском комплексе // Высшее образование в России. - 2009. - № 5. - С.27-41.

10. Квадрициус Н.В. Двухуровневая система высшего образования: Оценка с позиций теории человеческого капитала// Вестник СПбГУ. Сер. 5. 2006. Вып. 4. С. 151-156.

\footnotetext{
16 См.: Лапыгин Д.Ю., Корецкий Г.А. Контуры регионального образовательного кластера. // Экономика региона. 2007. - № 18. - С. 25.

17 См., напр.: Карамурзов Б.С. Непрерывное профессиональное образование в университетском комплексе // Высшее образование в России. - 2009. - № 5. - С. 27-41; Зернов В. Высшее образование как ресурс инновационного развития России // Высшее образование в России. - 2008. № 1 . - C.12-22.

18 См.: Асадуллин Р.М. Интеграция как новая форма сопряжения образования, науки и практики в регионе //Аккредитация в образовании. - 2009. - № 32. - С. 16-18.
}

\footnotetext{
19 См.: Филиппов П. Кластеры конкурентоспособности // Эксперт Северо-Запад. - № 43 (152) от 17 ноября 2003 года.

20 См.: Лагуткин А.В., Грудцына Л.Ю. Гражданское общество в современной России: проблемы роста // Представительная власть - XXI век: законодательство, комментарии, проблемы. 2013. № 2-3. С. 6-10.

21 См.: Вознесенская Е.Д. Чередниченко Г.А. Высшее образование в профессиональных траекториях молодых рабочих // Вопросы образования. 2012. № 4. С. 40-41.
} 
11. Лагуткин А.В. Вузы экстра-класстера // Московский Комсомолец. 2012. № 26130. 28 декабря.

12. Лагуткин А.В., Грудцына Л.Ю. Гражданское общество в современной России: проблемы роста // Представительная власть-XXI век: законодательство, комментарии, проблемы. 2013. № 2-3. С. 6-10.

13. Лапыгин Д.Ю., Корецкий Г.А. Контуры регионального образовательного кластера. // Экономика региона. - 2007. — № 18. - С. 25.

14. Портер М. Конкуренция. М.: Издат. дом «Вильяме», 2003.

15. Смирнов А.В. Образовательные кластеры и инновационное обучение в вузе. Монография. - Казань: РИЦ «Школа», 2010. - С. 5-6.

16. Трушников Д.Ю., Трушникова В.И. Воспитание в условиях университетского кластера и ценностные студенчества:Статья. [электронный ресурс].URL: http:// conference.tsogu.ru/static/articles/2009/01/_. doc (дата обращения 04.01.2010 г.).

17. Филиппов П. Кластеры конкурентоспособности // Эксперт Северо-Запад. — № 43 (152) от 17 ноября 2003 года.

18. Цихан Т.В. Кластерная теория экономического развития // Теория и практика управления. 2003. № 5.

19. Яворский О.Е. Образовательный кластер как форма социального партнерства техникума и предприятий газовой отрасли: диссертация ... кандидата педагогических наук: 13.00.01. - Казань, 2008. - 253 с.

20. Човган И.В. Анализ влияния процесса глобализации на обеспечение национальной безопасности государства в сфере высшего образования // NB: Вопросы права и политики. - 2013. - 5. - С. 135-149. DOI: 10.7256/2305-9699.2013.5.739. URL: http://www.e-notabene.ru/lr/article_739.html

21. Е. Н. Щербак Правовые проблемы государственного управления в области высшего образования в России в контексте развития образовательного рынка и глобализации // Политика и Общество. 2011. - 12. - С. $45-49$.

\section{References:}

1. Asadullin R.M. Integratsiya kak novaya forma sopryazheniya obrazovaniya, nauki i praktiki v regione // Akkreditatsiya v obrazovanii. — 2009. — № 32. - S. 16-18.

2. Voznesenskaya E.D. Cherednichenko G.A. Vysshee obrazovanie v professional'nykh traektoriyakh molodykh rabochikh // Voprosy obrazovaniya. 2012. № 4. S. 40-41.

3. Gavrilova O.E., Shageeva F.T., Nikitina L.L. K voprosu o podgotovke spetsialistov-konstruktorov shveinogo proizvodstva v usloviyakh obrazovatel'nogo klastera. - [elektronnyi resurs]. URL: http://conference.kemsu. $\mathrm{ru} /$ GetDocsFile?id=13537\&table= papers_file\&type=0\&conn=confDB (data obrashcheniya 02.01.2010g.).

4. Gromyko Yu.V. Chto takoe klastery i kak ikh sozdavat'? // Al'manakh «Vostok». — 2007. — Vyp.1. [elektronnyi resurs]. URL: http://www.situation.ru/app/j_artp_1178.htm.

5. Grudtsyna L.Yu. Gosudarstvenno-pravovoi mekhanizm formirovaniya i podderzhki institutov grazhdanskogo obshchestva v Rossii / Avtoref. diss... dokt. yurid. nauk / Rossiiskii universitet druzhby narodov (RUDN). Moskva, 2009.

6. Grudtsyna L.Yu. Reformirovanie sistemy attestatsii nauchnykh i nauchno-pedagogicheskikh kadrov: nekotorye predlozheniya // Gosudarstvo i pravo. 2013. № 3. S. 5-19.

7. Zernov V. Vysshee obrazovanie kak resurs innovatsionnogo razvitiya Rossii // Vysshee obrazovanie v Rossii. 2008. - № 1. - S. 12-22.

8. Kapelyushnikov R.I. Tsenitsya li na rossiiskom rynke chelovecheskii kapital? (http://www.demoscope.ru/ weekly/2005/0193/tema01.php).

9. Karamurzov B.S. Nepreryvnoe professional'noe obrazovanie v universitetskom komplekse // Vysshee obrazovanie v Rossii. — 2009. - № 5. - S. 27-41.

10. Kvadritsius N.V. Dvukhurovnevaya sistema vysshego obrazovaniya: Otsenka s pozitsii teorii chelovecheskogo kapitala// Vestnik SPbGU. Ser. 5. 2006. Vyp. 4. S. 151-156.

11. Lagutkin A.V. Vuzy ekstra-klasstera // Moskovskii Komsomolets. 2012. № 26130. 28 dekabrya.

12. Lagutkin A.V., Grudtsyna L.Yu. Grazhdanskoe obshchestvo v sovremennoi Rossii: problemy rosta // Predstavitel'naya vlast'-XXI vek: zakonodatel'stvo, kommentarii, problemy. 2013. № 2-3. S. 6-10.

13. Lapygin D.Yu., Koretskii G.A. Kontury regional'nogo obrazovatel'nogo klastera. // Ekonomika regiona. 2007. — № 18. - S. 25. 


\section{Административное и муниципальное право 7 (79) 2014}

14. Porter M. Konkurentsiya. M.: Izdat. dom «Vil'yame», 2003.

15. Smirnov A.V. Obrazovatel'nye klastery i innovatsionnoe obuchenie v vuze. Monografiya. - Kazan': RITs «Shkola», 2010. - S. 5-6.

16. Trushnikov D.Yu., Trushnikova V.I. Vospitanie $\mathrm{v}$ usloviyakh universitetskogo klastera i tsennostnye studenchestva: Stat'ya. [elektronnyi resurs]. URL: http:// conference.tsogu.ru/static/articles/2009/01/_. doc (data obrashcheniya 04.01.2010g.).

17. Filippov P. Klastery konkurentosposobnosti // Ekspert Severo-Zapad. — № 43 (152) ot 17 noyabrya 2003 goda.

18. Tsikhan T.V. Klasternaya teoriya ekonomicheskogo razvitiya // Teoriya i praktika upravleniya. 2003. № 5.

19. Yavorskii O.E. Obrazovatel'nyi klaster kak forma sotsial'nogo partnerstva tekhnikuma i predpriyatii gazovoi otrasli: dissertatsiya ... kandidata pedagogicheskikh nauk: 13.00.01. — Kazan', 2008. — 253 s.

20. Chovgan I.V. Analiz vliyaniya protsessa globalizatsii na obespechenie natsional'noi bezopasnosti gosudarstva v sfere vysshego obrazovaniya // NB: Voprosy prava i politiki. - 2013. - 5. - C. 135-149. DOI: 10.7256/23059699.2013.5.739. URL: http://www.e-notabene.ru/lr/article_739.html

21. E. N. Shcherbak Pravovye problemy gosudarstvennogo upravleniya $\mathrm{v}$ oblasti vysshego obrazovaniya $\mathrm{v}$ Rossii v kontekste razvitiya obrazovatel'nogo rynka i globalizatsii // Politika i Obshchestvo. — 2011. — 12. — C. 45-49. 